\title{
Diffusion coefficients of natural gas in foamy oil systems under high pressures
}

\author{
Yan-Yu Zhang ${ }^{1} \cdot$ Xiao-Fei Sun ${ }^{1,2,3} \cdot$ Xue-Wei Duan ${ }^{1} \cdot$ Xing-Min $\mathrm{Li}^{4}$
}

Received: 18 May 2014/Published online: 11 April 2015

(c) The Author(s) 2015. This article is published with open access at Springerlink.com

\begin{abstract}
The diffusion coefficient of natural gas in foamy oil is one of the key parameters to evaluate the feasibility of gas injection for enhanced oil recovery in foamy oil reservoirs. In this paper, a PVT cell was used to measure diffusion coefficients of natural gas in Venezuela foamy oil at high pressures, and a new method for determining the diffusion coefficient in the foamy oil was developed on the basis of experimental data. The effects of pressure and the types of the liquid phase on the diffusion coefficient of the natural gas were discussed. The results indicate that the diffusion coefficients of natural gas in foamy oil, saturated oil, and dead oil increase linearly with increasing pressure. The diffusion coefficient of natural gas in the foamy oil at $20 \mathrm{MPa}$ was 2.93 times larger than that at $8.65 \mathrm{MPa}$. The diffusion coefficient of the natural gas in dead oil was 3.02 and 4.02 times than that of the natural gas in saturated oil and foamy oil when the pressure was $20 \mathrm{MPa}$. However, the gas content of foamy oil was 16.9 times higher than that of dead oil when the dissolution time and pressure were $20 \mathrm{MPa}$ and $35.22 \mathrm{~h}$, respectively.
\end{abstract}

Xiao-Fei Sun

sunxiaofei540361@163.com

1 College of Petroleum Engineering, China University of Petroleum, Qingdao 266580, Shandong, China

2 School of Geosciences, China University of Petroleum, Qingdao 266580, Shandong, China

3 The Department of Chemical and Petroleum Engineering, University of Calgary, Calgary, AB T2N 1N4, Canada

4 Research Institute of Petroleum Exploration and Development, PetroChina, Beijing 100083, China

Edited by Yan-Hua Sun
Keywords Foamy oil · Diffusion coefficient · Heavy oil · Gas injection · High pressure

\section{Introduction}

Field trials in China, Venezuela, and Canada have shown that the primary depletion production of several heavy oil reservoirs is anomalous compared to conventional oil reservoirs under solution gas drive. Once below the equilibrium bubble point pressure, the producing gas-oil ratio (GOR) increases slowly, and a higher primary recovery factor $(5 \%-25 \%)$ than expected has been reported from some of those reservoirs (Guan et al. 2008; Mu et al. 2009; Mu 2010; Li et al. 2012; Liu et al. 2013b). The most plausible explanation of this anomalous behavior appears to be the foamy oil phenomenon. Such phenomenon occurs when the solution gas is released from oil to form small dispersed, trapped gas bubbles inside the oil which flow with the oil because of the high viscosity of heavy oil. As a result, the oil is expanded and its viscosity is reduced due to gas bubbles (Yu and Shen 2008; Peng et al. 2009; Wang et al. 2009; Torabi et al. 2012). However, when the reservoir pressure is below the pseudo-bubble point pressure, the gasoil ratio of the reservoir increases quickly, and the oil production rate decreases sharply because the gas bubbles trapped in the oil begin to coalesce together to form free gas phase (Liu et al. 2011; Sun et al. 2013).

Natural gas injection is regarded as one of the most effective methods for enhancing heavy oil recovery after primary production (Garcia 1983; Xu et al. 2009; Zhu et al. 2010; Guo et al. 2010a; Dong et al. 2013). That is because natural gas can take advantage of residual solution gas in the reservoir after primary production, as well as many mechanisms involved in the gas injection process, such as, oil viscosity reduction, oil swelling, and foamy oil 
formation. However, doubts arose about whether the injected gas is able to dissolve into the oil by molecular diffusion and enhance oil recovery by the above-mentioned mechanisms. To overcome these doubts, the emphasis should be made on the accurate and convenient prediction of diffusion coefficients of natural gas in foamy oil, which is one of the most important parameter to evaluate the potential of gas injection process for foamy oil reservoirs after primary production (Zhang et al. 2000).

In the literature, there are many methods for predicting diffusion coefficients of gases in hydrocarbon systems. These methods can be roughly categorized into direct and indirect methods. In the first category, first measurements of diffusion coefficients were performed by Hill and Lacey (1934) for the methane-decane system at low pressures. Later, Woessner et al. (1969) reported some experimental data for gases in heavy oil and bitumen at reservoir pressure. The above-mentioned direct methods involve compositional analysis of liquid samples extracted at different times during the diffusion process, which is tedious and expensive. To eliminate this requirement, Riazi (1996) developed a simple and indirect way to predict diffusion coefficients of gasesthe pressure decay method. It is an experimental method for predicting diffusion coefficients of gases in liquids using a PVT cell. The step changes in the pressure within the PVT cell in combination with a developed mathematical model were used to predict the diffusion coefficients. Later, Jamialahmadi et al. (2006) and Etminan et al. (2010) reported a new method for predicting diffusion coefficients of gases in heavy oil from experimental volume-time profiles. In this method, the volume changes of the PVT cell were recorded and used to calculate diffusion coefficients of gases in liquid hydrocarbon systems instead of the pressure changes.

The present investigations systematically estimate the molecular diffusion of gases, such as methane and $\mathrm{CO}_{2}$, in dead oils (those with very little dissolved gas) at low pressures. Experimental data on molecular diffusion at high pressures are scarce, at least in part, because conducting these experiments is difficult, expensive, and time consuming, and none of the available experimental data on molecular diffusion and methods is suitable for the prediction of diffusion coefficients of natural gas in foamy oil at high pressures. In this paper, a high pressure PVT cell was used to measure diffusion coefficients of natural gas in typical Venezuela foamy oil at high pressures $(5,8.65,12,16$, $20 \mathrm{MPa}$ ). Furthermore, a new method for determining the diffusion coefficients of natural gas in foamy oil, saturated oil, and dead oil was developed on the basis of experimental data. This paper provides a better understanding of the diffusion process of natural gas in foamy oil and the effects of types of the liquid phase and pressure on the diffusion coefficient of natural gas, which is a critical factor for feasibility evaluation of the gas injection process in foamy oil reservoirs after primary production.

\section{Experimental}

The oil state in porous media is related to reservoir pressure of foamy reservoirs, as shown in Fig. 1. When the reservoir pressure is above the bubble point pressure $\left(P_{\mathrm{b}}\right)$, the gas exists as solution gas in the oil phase. Thus, the oil is in the saturated state. Once the reservoir pressure is below the bubble-point pressure, the released solution gas is trapped and dispersed in oil. The oil is foamy and is in a pseudoundersaturated state. As the reservoir pressure reaches the pseudo-bubble-point pressure $\left(P_{\mathrm{pb}}\right)$, the dispersed gas in the heavy oil disengages from oil completely and becomes a movable phase. The oil in some part of the reservoir becomes dead oil after the gas is produced by the wells. In order to understand the natural gas diffusion process in foamy oil which is different from that in saturated oil and dead oil, and to determine the injection timing (reservoir pressure) for gas injection, diffusion coefficients of natural gas in saturated oil, foamy oil, and dead oil at high pressures were measured with a high-pressure PVT apparatus.

\subsection{Experimental materials and setup}

Crude oil from the MPE3 reservoir in the Orinoco Belt, Venezuela was supplied by China National Petroleum

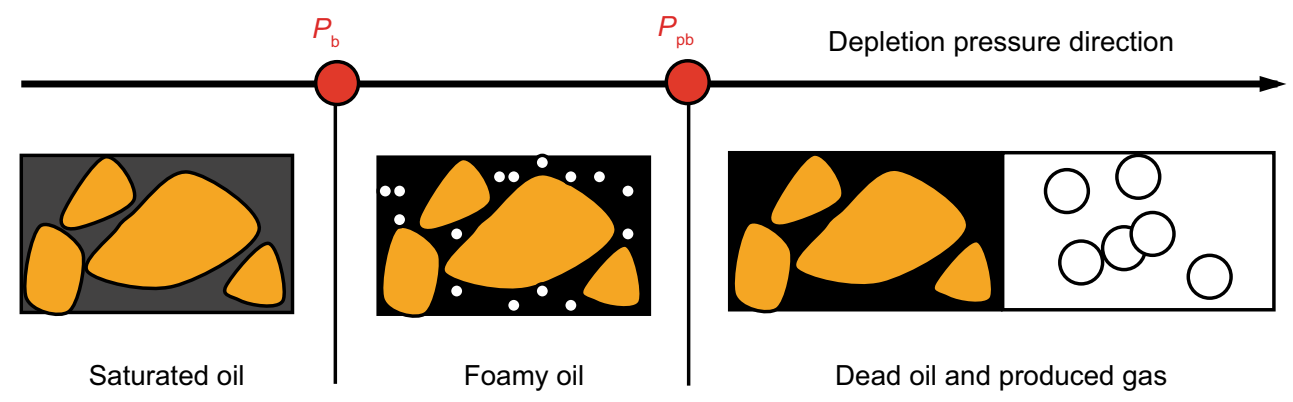

Fig. 1 Three oil states during the production process of foamy oil reservoirs 
Table 1 Summary of fluid samples from the MPE3 block in Venezuela

\begin{tabular}{lll}
\hline Flash data & $\mathrm{GOR}, \mathrm{m}^{3} / \mathrm{m}^{3}$ & 15 \\
Viscosity, mPa s & Dead oil density, g/cm $\mathrm{cm}^{3}$ & 1.013 \\
& $@ 50{ }^{\circ} \mathrm{C}$ & 24,715 \\
& $@ 65{ }^{\circ} \mathrm{C}$ & 5559 \\
& $@ 80^{\circ} \mathrm{C}$ & 1620 \\
Recombined oil properties & @ $95{ }^{\circ} \mathrm{C}$ & 644 \\
& $\mathrm{FVF}, \mathrm{m}^{3} / \mathrm{m}^{3}$ & 1.173 \\
& Density, $\mathrm{g} / \mathrm{cm}^{3}$ & 0.957 \\
& Bubble pressure, MPa & 4.95 \\
& Pseudo bubble pressure, MPa & \\
& $@ 60 \mathrm{~min}$ for each depletion step & 3.44 \\
& $@ 12 \mathrm{~h}$ for each depletion step & 2.74 \\
& @ 1 days for each depletion step & 1.89 \\
\hline
\end{tabular}

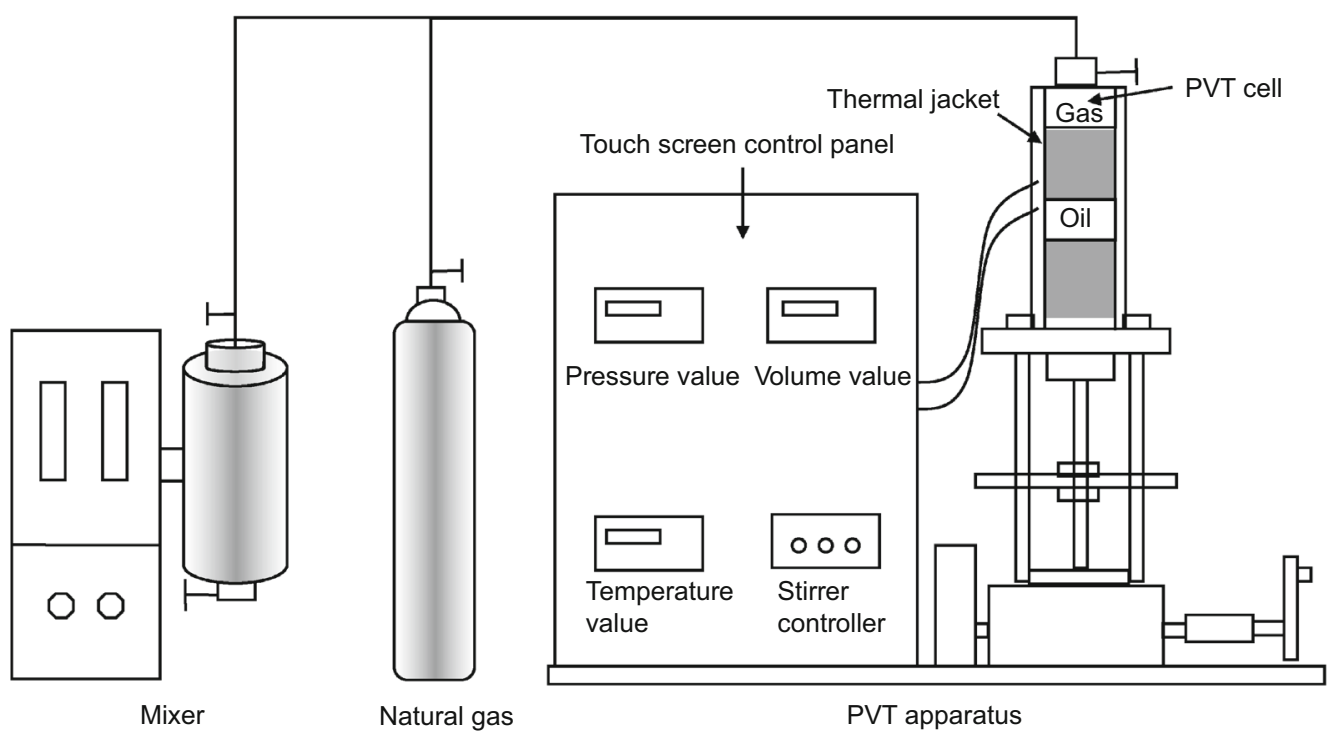

Fig. 2 Diagram of the experimental apparatus for gas diffusion experiments

Corporation, which can easily form foamy oil during production (Bondino et al. 2009; Guo et al. 2010b). According to flashed gas component analysis, methane and carbon dioxide account for $86.7 \%$ and $10.8 \%$, respectively. Therefore, the natural gas used in experiments consisted of methane and carbon dioxide with a volume ratio of 8:1. The crude oil was recombined with natural gas at the reservoir temperature and pressure $\left(54.2{ }^{\circ} \mathrm{C}\right.$ and $8.65 \mathrm{MPa}$, respectively) to yield recombined reservoir oil for use in gas diffusion experiments. Table 1 lists the fluid characteristics of dead oil and recombined oil. The bubble pressure and pseudo-bubble pressures are important parameters for determination of the foamy oil state in the reservoir which were estimated by relative volume versus pressure curves in the conventional and unconventional PVT tests (Sun et al. 2013).

The experimental apparatus used for this study is shown schematically in Fig. 2. It is a traditional PVT apparatus
(Haian HWGX-60) designed for operation at high temperatures and high pressures. The internal cross-sectional area of the PVT cell is $8.33 \mathrm{~cm}^{2}$ and the cell height is $30.0 \mathrm{~cm}$. The apparatus provides the pressure, total volume, and temperature values on a touch-screen control panel. The volume of the PVT cell and its pressure can be adjusted by a pump which is controlled by means of a hand-actuated piston or electrically. The fluids in the cell can be mixed vigorously using a magnetic stirrer at desired pressures and temperatures.

\subsection{Experimental procedures}

After the PVT cell was evacuated for $24 \mathrm{~h}$, the reconstituted oil was introduced into the cell from the mixer to obtain an oil column of a desired height, and the cell pressure and temperature were maintained at initial reservoir conditions 
(8.65 $\mathrm{MPa}$ and $54.2{ }^{\circ} \mathrm{C}$, respectively). Then, the cell pressure decreased to current reservoir pressure (4.0 $\mathrm{MPa}$ ) which was between the bubble pressure and pseudo-bubble pressure (Table 1). The unconventional method was used to simulate the foamy oil behavior, that is the PVT cell was not rocked, avoiding a rapid artificial nucleation of the gas micro-bubbles and hence forming a separated gas phase. In this way, the oil would be a pseudo-phase that contains oil and gas bubbles trapped within the oil (foamy oil). A day later, natural gas was injected slowly into the PVT cell from the top until the cell pressure rose to 5.0 $\mathrm{MPa}$. Because the injection gas dissolved into the oil, the cell pressure decreased correspondingly. The volume of the PVT cell was adjusted and recorded to maintain the cell pressure constant. When the PVT cell pressure stayed constant over a period of time, the equilibrium between the gas phase and the aqueous phase was considered to be reached. The natural gas dissolution tests were started from a low pressure. After the first measurement, the above natural gas diffusion process was carried out at 4 higher cell pressures $(8.65,12,16$, and $20 \mathrm{MPa})$.

Natural gas diffusion experiments in saturated oil and dead oil at the same pressures were studied in a similar process except the method to simulate saturated oil and dead oil before the diffusion process. The saturated oil was simulated by decreasing the cell pressure from the reservoir pressure to 4.0 $\mathrm{MPa}$, and disengaging the released solution gas from oil by strong agitation in the PVT cell. The dead oil was made by decreasing the cell pressure to atmospheric pressure to release all the solution gas in the recombined oil, and then the cell pressure increased to $4.0 \mathrm{MPa}$.

\section{Experimental results and discussion}

The gas contents and cumulative diffusion volumes of the foamy oil, saturated oil, and dead oil with time measured in experiments at different pressures are presented in Tables 2, 3 and 4 and Figs. 3, 4 and 5 .

In all cases, the cumulative diffusion volumes of natural gas in three types of oils at different pressures show a similar tendency with time, which can be roughly divided into two stages (Figs. 3, 4, 5). The cumulative diffusion volumes of natural gas in these three types of oils rose sharply at the initial stage. Subsequently, the cumulative diffusion volumes kept increasing, but increased slowly compared with the initial stage.

Pressure had an important effect on gas diffusion in foamy oil, saturated oil, and dead oil. The cumulative diffusion volumes and gas contents of the three types of oil increased with an increase in pressure. For gas diffusion in foamy oil, the cumulative diffusion volume at $20 \mathrm{MPa}$ was 4.8 times of that at $8.65 \mathrm{MPa}$ when the diffusion time was $35.22 \mathrm{~h}$. The cumulative diffusion volumes of gas in dead oil were larger than that in saturated oil and foamy oil at the same pressure and time. When the dissolution time was $35.22 \mathrm{~h}$, the cumulative dissolution volume of gas in dead oil was 1.43 times larger than that in foamy oil, indicating that natural gas has a better diffusion capacity in dead oil than in foamy oil. However, the gas content in foamy oil was higher than that in saturated oil and dead oil. For example, when the dissolution time and pressure were $35.22 \mathrm{~h}$ and $20 \mathrm{MPa}$, the gas content in foamy oil was 1.11 and 16.93 times higher than that in saturated oil and dead oil. This increase is because of the foamy oil system which is a non-equilibrium system and has an amount of trapped gas and solution gas. For this reason, it is harder for natural gas to diffuse into foamy oil.

\section{Mathematical model}

Descriptions for gas diffusion in foamy oil, saturated oil, and dead oil are schematically shown in Fig. 6. The major assumptions are as follows:

1) Swelling of foamy oil, saturated oil, and dead oil caused by gas solution is negligible.

2) The concentration at the interface is the equilibrium concentration.

3) The PVT cell temperature is constant during gas diffusion.

4) The diffusion coefficient does not change significantly with concentration over the range of concentrations encountered in the test.

5) The foamy oil, saturated oil, and dead oil are nonvolatile, and the natural gas is assumed to be a single component gas.

6) When the natural gas is injected into the PVT cell, the dispersed gas in foamy oil dissolves instantaneously into the liquid phase.

Molecular diffusion of gases in oil plays a role in heavy oil recovery processes, such as solution gas drive and gas flooding. In order to corroborate experimental results and predicate diffusion coefficients of natural gas in foamy oil, saturated oil, and dead oil, a model for a one-dimensional diffusion PVT cell without chemical reaction was used as follows:

$\frac{\partial C}{\partial t}=D \frac{\partial^{2} C}{\partial x^{2}}$

where $C$ is the mass concentration of solute, $\mathrm{kg} / \mathrm{m}^{3} ; D$ is the diffusion coefficient, $\mathrm{m}^{2} / \mathrm{s} ; x$ is the coordinate direction, $\mathrm{m}$; $t$ is time, s.

Before diffusion of gas in oil, the concentration of gas in foamy oil $\left(C_{\mathrm{i}}\right)$ is assumed to have two parts according to the characteristics of foamy oil: (1) $C_{\text {solution }}$ is the 
Table 2 Gas content (GC) in foamy oil versus time at different pressures

\begin{tabular}{|c|c|c|c|c|c|c|c|c|c|}
\hline \multicolumn{2}{|l|}{$5 \mathrm{MPa}$} & \multicolumn{2}{|c|}{$8.65 \mathrm{MPa}$} & \multicolumn{2}{|l|}{$12 \mathrm{MPa}$} & \multicolumn{2}{|l|}{$16 \mathrm{MPa}$} & \multicolumn{2}{|l|}{$20 \mathrm{MPa}$} \\
\hline Time, $\mathrm{h}$ & $\mathrm{GC}, \mathrm{cm}^{3}$ & Time, h & $\mathrm{GC}, \mathrm{cm}^{3}$ & Time, h & $\mathrm{GC}, \mathrm{cm}^{3}$ & Time, $\mathrm{h}$ & $\mathrm{GC}, \mathrm{cm}^{3}$ & Time, h & $\mathrm{GC}, \mathrm{cm}^{3}$ \\
\hline 0.17 & 41.14 & 0.17 & 41.19 & 0.08 & 41.29 & 0.08 & 41.46 & 0.08 & 41.43 \\
\hline 0.33 & 41.18 & 0.33 & 41.23 & 0.09 & 41.3 & 0.42 & 41.74 & 0.22 & 41.90 \\
\hline 0.83 & 41.19 & 0.83 & 41.24 & 0.14 & 41.32 & 0.75 & 41.94 & 0.38 & 42.16 \\
\hline 1.17 & 41.21 & 1.00 & 41.25 & 0.17 & 41.35 & 0.92 & 42.1 & 0.55 & 42.19 \\
\hline 1.33 & 41.21 & 1.17 & 41.26 & 0.25 & 41.37 & 1.08 & 42.12 & 0.72 & 42.27 \\
\hline 12.33 & 41.25 & 1.33 & 41.26 & 0.42 & 41.4 & 1.25 & 42.13 & 1.05 & 42.34 \\
\hline 18.83 & 41.27 & 2.33 & 41.26 & 0.58 & 41.42 & 1.42 & 42.1 & 1.22 & 42.41 \\
\hline 23.83 & 41.28 & 12.33 & 41.3 & 1.08 & 41.45 & 1.58 & 42.16 & 1.55 & 42.42 \\
\hline 26.83 & 41.28 & 18.83 & 41.33 & 2.47 & 41.45 & 2.75 & 42.22 & 1.72 & 42.52 \\
\hline 37.33 & 41.30 & 23.83 & 41.35 & 15.47 & 41.56 & 3.75 & 42.24 & 8.00 & 42.59 \\
\hline 42.83 & 41.31 & 26.83 & 41.42 & 17.98 & 41.62 & 4.75 & 42.26 & 11.72 & 42.64 \\
\hline 50.00 & 41.33 & 37.33 & 41.44 & 29.47 & 41.74 & 28.75 & 42.46 & 17.72 & 42.72 \\
\hline 55.00 & 41.35 & 42.83 & 41.53 & 46.47 & 41.95 & 46.75 & 42.54 & 35.22 & 42.84 \\
\hline
\end{tabular}

Table 3 Gas content (GC) in saturated oil versus time at different pressures

\begin{tabular}{|c|c|c|c|c|c|c|c|c|c|}
\hline \multicolumn{2}{|l|}{$5 \mathrm{MPa}$} & \multicolumn{2}{|c|}{$8.65 \mathrm{MPa}$} & \multicolumn{2}{|l|}{$12 \mathrm{MPa}$} & \multicolumn{2}{|l|}{$16 \mathrm{MPa}$} & \multicolumn{2}{|l|}{$20 \mathrm{MPa}$} \\
\hline Time, $\mathrm{h}$ & $\mathrm{GC}, \mathrm{cm}^{3}$ & Time, $\mathrm{h}$ & $\mathrm{GC}, \mathrm{cm}^{3}$ & Time, $\mathrm{h}$ & $\mathrm{GC}, \mathrm{cm}^{3}$ & Time, $\mathrm{h}$ & $\mathrm{GC}, \mathrm{cm}^{3}$ & Time, $\mathrm{h}$ & $\mathrm{GC}, \mathrm{cm}^{3}$ \\
\hline 0.10 & 36.50 & 0.12 & 36.52 & 0.17 & 36.82 & 0.08 & 37.17 & 0.12 & 37.51 \\
\hline 0.28 & 36.54 & 0.28 & 36.54 & 0.33 & 36.93 & 0.17 & 37.32 & 0.20 & 37.76 \\
\hline 0.50 & 36.56 & 0.50 & 36.55 & 0.50 & 36.97 & 0.33 & 37.45 & 0.37 & 37.87 \\
\hline 0.98 & 36.67 & 0.98 & 36.67 & 1.00 & 37.00 & 0.50 & 37.56 & 0.53 & 37.97 \\
\hline 2.70 & 36.75 & 1.50 & 36.79 & 1.75 & 37.04 & 0.83 & 37.63 & 1.00 & 38.03 \\
\hline 6.20 & 36.77 & 2.70 & 36.85 & 3.00 & 37.05 & 1.83 & 37.71 & 1.58 & 38.09 \\
\hline 16.60 & 36.80 & 6.20 & 36.9 & 5.75 & 37.1 & 2.83 & 37.76 & 2.08 & 38.09 \\
\hline 23.38 & 36.81 & 6.60 & 36.9 & 10.75 & 37.14 & 3.83 & 37.78 & 3.00 & 38.18 \\
\hline 50.00 & 36.87 & 23.38 & 36.96 & 15.00 & 37.19 & 4.83 & 37.8 & 3.40 & 38.2 \\
\hline 68.00 & 36.92 & 50.00 & 37.11 & 23.08 & 37.22 & 16.16 & 37.95 & 13.00 & 38.32 \\
\hline 73.00 & 36.94 & 78.00 & 37.2 & 40.00 & 37.34 & 25.53 & 37.97 & 26.50 & 38.44 \\
\hline 80.00 & 36.96 & 83.00 & 37.22 & 47.53 & 37.38 & 39.80 & 38.12 & 36.17 & 38.54 \\
\hline 85.00 & 36.97 & 90.00 & 37.25 & 51.00 & 37.42 & 45.00 & 38.16 & 60.00 & 38.76 \\
\hline
\end{tabular}

concentration of the solution gas, and (2) $C_{\text {dispersed }}$ is the concentration of the dispersed gas which is trapped in the oil phase. The concentration of gas in saturated oil $\left(C_{\mathrm{i}}\right)$ is the concentration of the solution gas, $C_{\text {solution. }}$ The concentration of gas in dead oil is negligible in that the solution gas was released from oil when the pressure was decreased to atmospheric pressure. Thus, the initial condition of the diffusion PVT cell is

Foamy oil:

$C_{\mathrm{i}}=C_{\text {solution }}+C_{\text {dispersed }}$

Saturated oil:

$C_{\mathrm{i}}=C_{\text {solution }} \quad$ for $t=0 \quad 0 \leq x \leq Z_{x}$

Dead oil:

$C_{\mathrm{i}}=0$
According to Whitman's theory (1923), the gas and liquid phases at the interface are thermodynamically in equilibrium. Thus, the concentration of gas at the interface, $C_{\mathrm{eq}}$, remains constant. The first boundary condition of Eq. (1) is $C=C_{\mathrm{eq}} \quad$ for $t>0 \quad x=Z_{0}$.

In these experiments, the natural gas cannot diffuse to reach the bottom of the PVT cell because diffusion coefficients of gas are sufficiently low and the experimental time is relatively short. Hence, the semi-infinite system assumption is valid. Hence, the second boundary condition of Eq. (1) can be defined as

$C=C_{\mathrm{i}} \quad$ for $x=0 \quad t \geq 0$.

The Laplace transform was applied to reducing the partial differential equation [Eq. (1)] using the initial 
Table 4 Gas content (GC) in dead oil versus time at different pressures

\begin{tabular}{|c|c|c|c|c|c|c|c|c|c|}
\hline \multicolumn{2}{|l|}{$5 \mathrm{MPa}$} & \multicolumn{2}{|c|}{$8.65 \mathrm{MPa}$} & \multicolumn{2}{|l|}{$12 \mathrm{MPa}$} & \multicolumn{2}{|l|}{$16 \mathrm{MPa}$} & \multicolumn{2}{|l|}{$20 \mathrm{MPa}$} \\
\hline Time, $\mathrm{h}$ & $\mathrm{GC}, \mathrm{cm}^{3}$ & Time, h & $\mathrm{GC}, \mathrm{cm}^{3}$ & Time, h & $\mathrm{GC}, \mathrm{cm}^{3}$ & Time, $\mathrm{h}$ & $\mathrm{GC}, \mathrm{cm}^{3}$ & Time, h & $\mathrm{GC}, \mathrm{cm}^{3}$ \\
\hline 0.08 & 0.04 & 0.08 & 0.09 & 0.50 & 0.62 & 0.50 & 1.20 & 0.15 & 1.30 \\
\hline 1.77 & 0.19 & 0.43 & 0.15 & 1.00 & 0.78 & 1.00 & 1.41 & 0.65 & 1.61 \\
\hline 2.27 & 0.28 & 0.77 & 0.19 & 2.00 & 0.83 & 2.00 & 1.51 & 2.15 & 1.80 \\
\hline 3.77 & 0.31 & 1.27 & 0.21 & 2.50 & 0.83 & 6.50 & 1.67 & 12.15 & 2.17 \\
\hline 8.47 & 0.52 & 1.77 & 0.24 & 4.50 & 0.93 & 11.50 & 1.79 & 24.65 & 2.36 \\
\hline 13.27 & 0.58 & 2.27 & 0.27 & 6.50 & 1.12 & 24.00 & 1.89 & 29.15 & 2.53 \\
\hline 14.27 & 0.59 & 3.77 & 0.51 & 11.50 & 1.21 & 33.50 & 1.99 & 35.65 & 2.56 \\
\hline 37.27 & 0.79 & 12.27 & 0.73 & 23.00 & 1.31 & 35.00 & 2.01 & 48.65 & 2.59 \\
\hline 51.00 & 0.90 & 13.27 & 0.77 & 33.00 & 1.40 & 54.00 & 2.24 & 54.00 & 2.71 \\
\hline 64.00 & 0.99 & 14.27 & 0.81 & 34.50 & 1.42 & 62.00 & 2.42 & 58.00 & 2.80 \\
\hline 70.00 & 1.05 & 37.27 & 0.91 & 54.00 & 1.68 & 65.00 & 2.45 & 60.00 & 2.86 \\
\hline 75.00 & 1.09 & 51.00 & 1.20 & 60.00 & 1.75 & 68.00 & 2.59 & 63.00 & 2.96 \\
\hline 80.00 & 1.13 & 54.00 & 1.25 & 65.00 & 1.90 & 70.00 & 2.63 & 67.00 & 3.05 \\
\hline
\end{tabular}

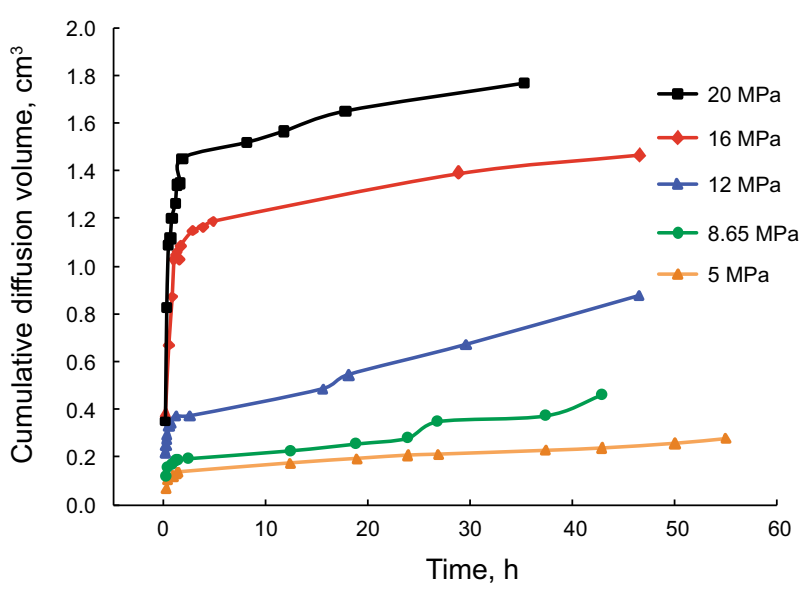

Fig. 3 Measured cumulative diffusion volumes of natural gas versus time for foamy oil

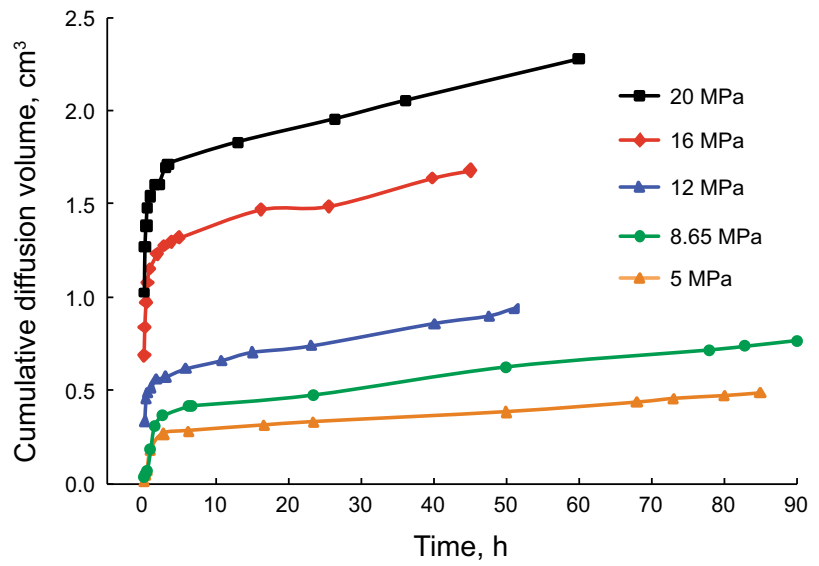

Fig. 4 Measured cumulative diffusion volumes of natural gas versus time for saturated oil

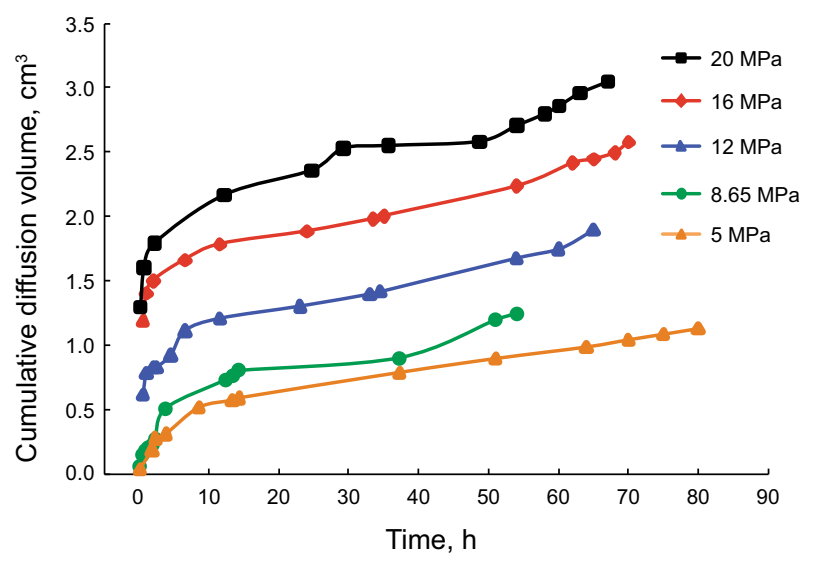

Fig. 5 Measured cumulative diffusion volumes of natural gas versus time for dead oil

conditions and an analytical closed form of the Laplace inverse is available as follows:

$C(x, t)=\left(C_{\mathrm{eq}}-C_{\mathrm{i}}\right) \operatorname{erfc}\left(\frac{x}{2 \sqrt{D t}}\right)+C_{\mathrm{i}}$,

where $C(x, t)$ is the solute concentration at position $x$ at time $t, \mathrm{~kg} / \mathrm{m}^{3}$.

The mass of the natural gas transferred into the oil phase after time $t$ can be calculated from the integration of Eq. (7) over the volume of the PVT cell:

$$
\begin{aligned}
m & =\int_{0}^{Z_{x}} C(x, t) \mathrm{d} V=A \int_{0}^{Z_{x}} C(x, t) \mathrm{d} x \\
& =2 S\left(C_{\text {eq }}-C_{\mathrm{i}}\right) \sqrt{\frac{D t}{\pi}}+m_{\mathrm{i}}=K \sqrt{t}+m_{\mathrm{i}},
\end{aligned}
$$




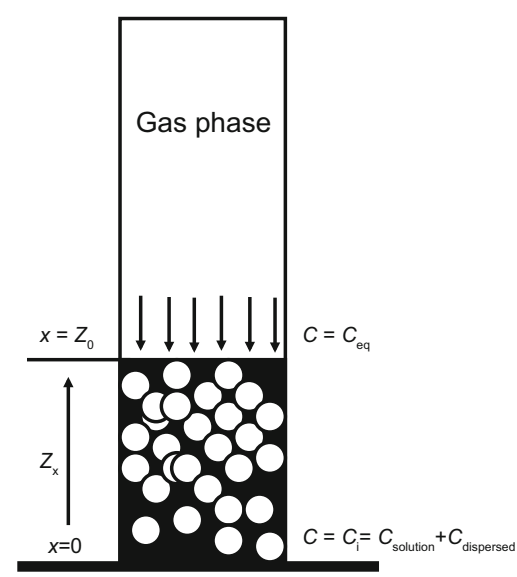

Foamy oil

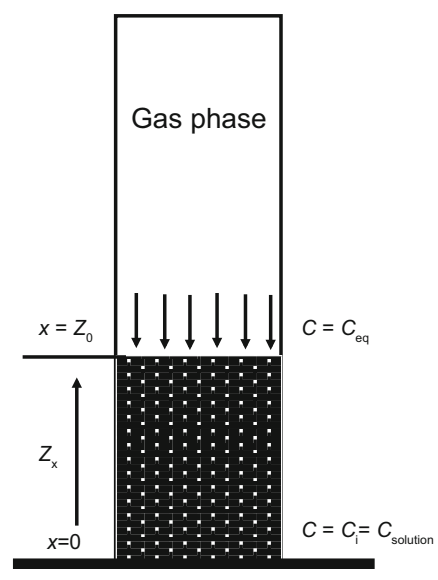

Saturated oil

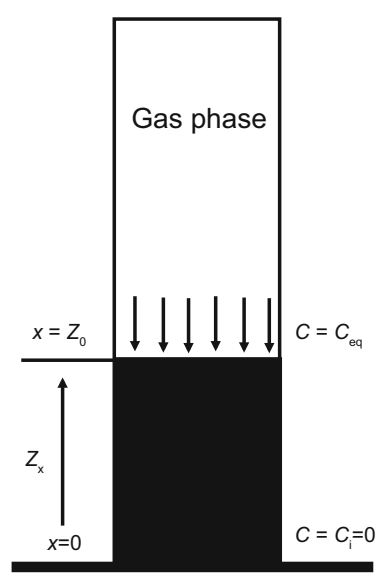

Dead oil

Fig. 6 Schematic and dimensions of diffusion process models

with

$K=2 A\left(C_{\mathrm{eq}}-C_{\mathrm{i}}\right) \sqrt{\frac{D}{\pi}}$,

where $m$ is the mass of the solute, $\mathrm{kg} ; A$ is the crosssectional area of the diffusion cell, $\mathrm{m}^{2}$.

According to Eq. (9), a plot of the mass of natural gas transferred into the oil phase versus the square root of time should provide a straight line with a slope of $K$. Thus, the diffusion coefficients of natural gas in foamy oil, saturated oil, and dead oil can be predicted from Eq. (9) by calculating the slope of $K$ from the experimental data.

\section{Determination of diffusion coefficients}

For the application of the model for determination of diffusion coefficients, gas compressibility factors under different pressures must be calculated based on the volume and the cross-sectional area of the cell, and the temperature and initial pressure of the system. Later, the interfacial concentration of gas $\left(C_{\mathrm{eq}}\right)$ and the initial concentration of gas in the liquid phase $\left(C_{\mathrm{i}}\right)$ should be determined by the characteristics of the three oil types. It is noted that the initial concentration of gas in foamy oil can be obtained from the trapped free gas coefficient $(\alpha)$ which represents the capability of the heavy oil to trap the released gas after depressurization. The factor is the volume of gas entrained in the foamy oil $(x-y)$ divided by volume of gas $(x)$ released after depressurization which can be obtained by comparing the GOR behavior with pressure in both conventional and unconventional differential liberation PVT tests (Fig. 7).

The volume of gas $(x)$ released after depressurization can be measured from the GOR obtained from a conventional differential liberation PVT test shown in Fig. 7. During this test, the oil and gas are under equilibrium conditions. Thus, the gas released is the maximum quantity at every pressure. For the unconventional differential liberation PVT test, the volume of the released gas existing as free gas bubbles $(y)$ can be measured. Therefore, the volume of gas entrained in foamy oil can be estimated by subtracting the released gas (y) during an unconventional differential liberation PVT test from the volume of gas $(x)$ released in a conventional differential liberation PVT test. The initial concentration of gas in saturated oil shown in Eq. (3) can be determined by the conventional differential liberation PVT test (Wang et al. 2012; Mohammad et al. 2012; Liu et al. 2013a).

After determination of all the parameters mentioned above in Eq. (9), the mass $m$ of foamy oil, saturated oil, and dead oil were plotted against the square root of time $\sqrt{t}$ as shown in Figs. 8, 9 and 10.

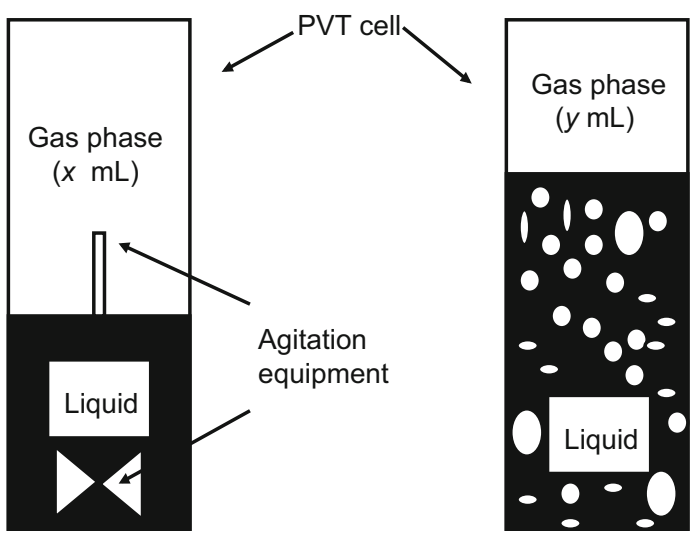

Strong agitation

No agitation

Conventional differential liberation test

Unconventional differential liberation test

Fig. 7 Schematic comparison of conventional and unconventional PVT tests showing the method to determine the initial concentration of gas in the foamy oil 


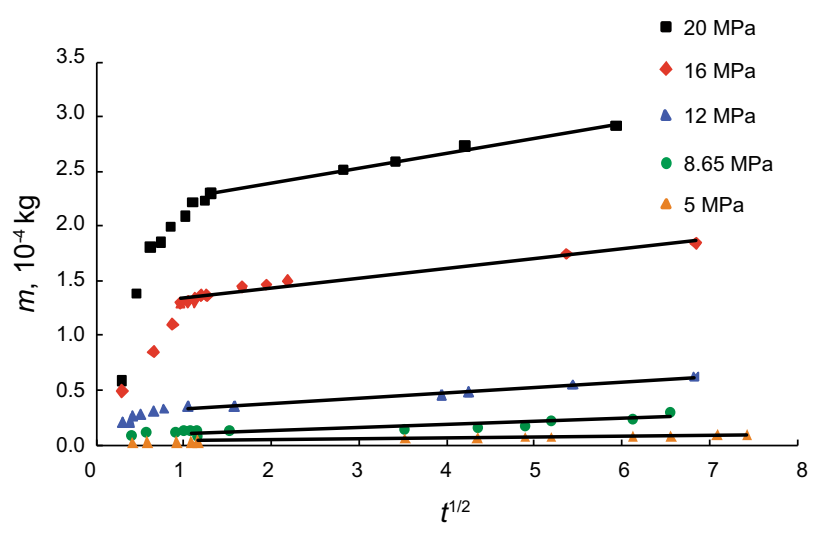

Fig. 8 Estimation of diffusion coefficients of natural gas in foamy oil at different pressures using Eq. (9)

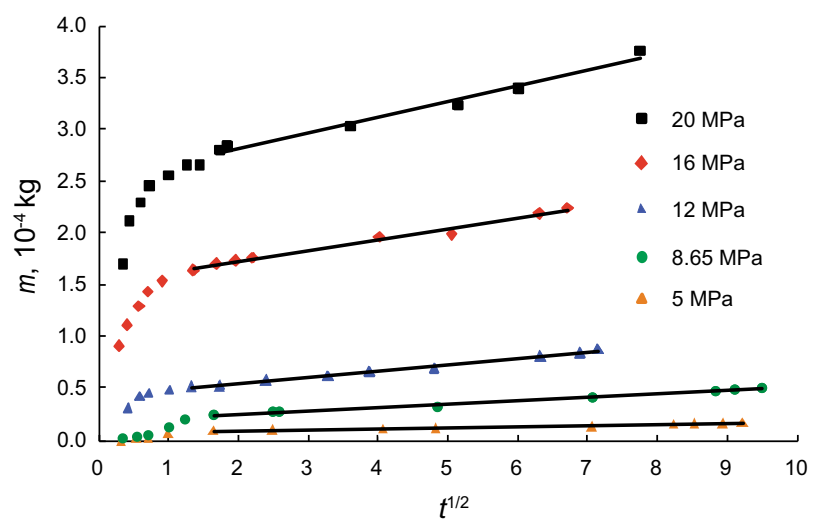

Fig. 9 Estimation of diffusion coefficients of natural gas in saturated oil at different pressures using Eq. (9)

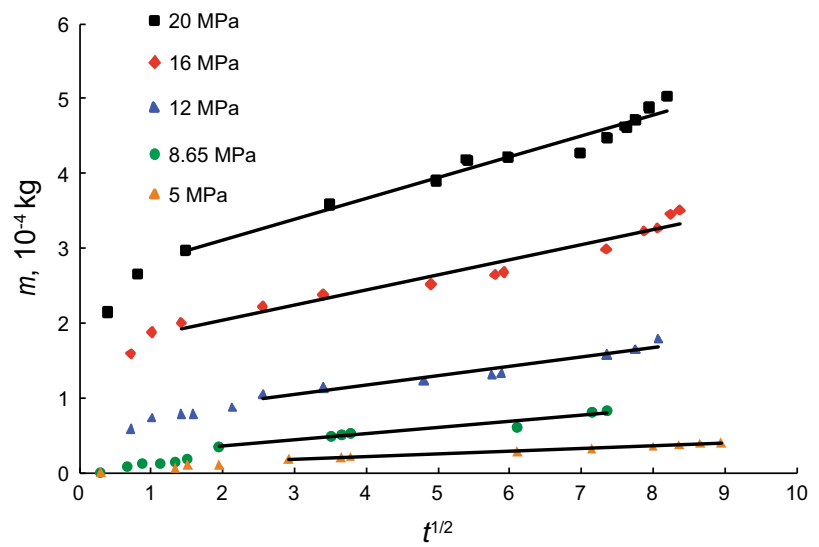

Fig. 10 Estimation of diffusion coefficients of natural gas in dead oil at different pressures using Eq. (9)

It is seen that experimental plots $m$ versus $\sqrt{t}$ can be divided into two stages in Figs. 8, 9 and 10. The early stages of diffusion are often affected by convective mixing arising from initially high mass transfer rates and surface tension-driven instabilities. This initial period or "incubation period" (Renner 1988) increases as the operating pressure increases. Since the effects of the incubation period decay with increasing contact time, middle and late time data are more reliable for estimation of diffusion coefficients from the experimental data. The diffusion coefficients were determined from the slopes of these straight lines by Eq. (9). The results of these calculations are given in Table 5 and Fig. 11 as a function of pressure for foamy oil, saturated oil, and dead oil.

The following information can be obtained from Fig. 11 and Table 5:

(1) It can be seen from $R^{2}$ shown in Table 5 that all experimental data in the plots $m$ versus $\sqrt{t}$ conform well to the straight lines after the incubation period, which corroborates that the proposed model is suitable to determine diffusion coefficients of gas in foamy oil, saturated oil, and dead oil.

(2) Diffusion coefficients of natural gas in foamy oil, saturated oil, and dead oil increase steadily with increasing operating pressure. The diffusion coefficients of natural gas in foamy oil at 20 and $8.65 \mathrm{MPa}$ are $5.53 \times 10^{-9}$ and $1.89 \times 10^{-9} \mathrm{~m}^{2} / \mathrm{s}$, respectively, indicating that diffusion coefficient of natural gas in foamy oil at $20 \mathrm{MPa}$ is 2.93 times larger than that at $8.65 \mathrm{MPa}$.

(3) A comparison of diffusion coefficients of natural gas in foamy oil, saturated oil, and dead oil at the same pressure indicates that diffusion coefficients of natural gas in foamy oil are lower than that of gas in saturated oil and dead oil. For example, the diffusion coefficients of natural gas in dead oil are 3.02 and 4.02 times than that of gas in saturated oil and foamy oil when the pressure is $20 \mathrm{MPa}$. This is the reason why the cumulative diffusion volume of gas in dead oil is larger than that of gas in saturated oil and foamy oil.

(4) From Fig. 11, it is observed that diffusion coefficients of natural gas in foamy oil, saturated oil and dead oil increase linearly with increasing operating pressure. The slope of the straight line for dead oil is larger than that for saturated oil and foamy oil. This means that the growth rate of the diffusion coefficient with increasing pressure in foamy oil is less than that in saturated oil and dead oil.

Several investigators have reported the diffusivity of methane and carbon dioxide in bitumens and heavy oils. However, these results are molecular diffusion of gases in dead oils at low pressures. Thus, in order to prove the validity of experimental results, correlation of gas diffusion coefficient in dead oil (Fig. 11) determined using the 
Table 5 Diffusion coefficients of natural gas in foamy oil, saturated oil, and dead oil

\begin{tabular}{llllc}
\hline Pressure, MPa & Oil type & Slope & $R^{2}$ & $\begin{array}{l}\text { Diffusion coefficient, } \\
10^{-9} \mathrm{~m}^{2} / \mathrm{s}\end{array}$ \\
\hline 20 & Foamy oil & 0.0000130 & 0.9956 & 5.53 \\
& Saturated oil & 0.0000151 & 0.9797 & 7.36 \\
& Dead oil & 0.0000278 & 0.9199 & 22.41 \\
& Foamy oil & 0.0000090 & 0.9704 & 4.87 \\
& Saturated oil & 0.0000105 & 0.9854 & 5.58 \\
12 & Dead oil & 0.0000202 & 0.9451 & 17.92 \\
& Foamy oil & 0.0000049 & 0.8483 & 2.66 \\
& Saturated oil & 0.0000060 & 0.9902 & 3.88 \\
& Dead oil & 0.0000125 & 0.9381 & 13.73 \\
& Foamy oil & 0.0000028 & 0.9864 & 1.89 \\
& Saturated oil & 0.0000033 & 0.9866 & 2.52 \\
& Dead oil & 0.0000082 & 0.9365 & 11.63 \\
& Foamy oil & 0.0000008 & 0.9711 & 0.73 \\
& Saturated oil & 0.0000010 & 0.9729 & 1.05 \\
& Dead oil & 0.0000036 & 0.9931 & 7.66 \\
\hline
\end{tabular}

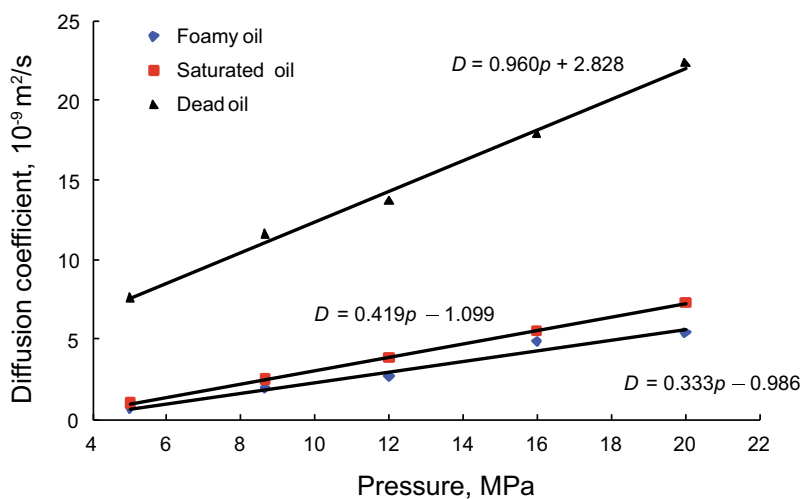

Fig. 11 Diffusion coefficients of natural gas in foamy oil, saturated oil, and dead oil as a function of pressure

equation of the straight line regression of experimental data is compared with the reported values for similar systems, shown in Table 6. A comparison (Fig. 12) shows that the correlation of natural gas diffusivities in Orinoco heavy oil

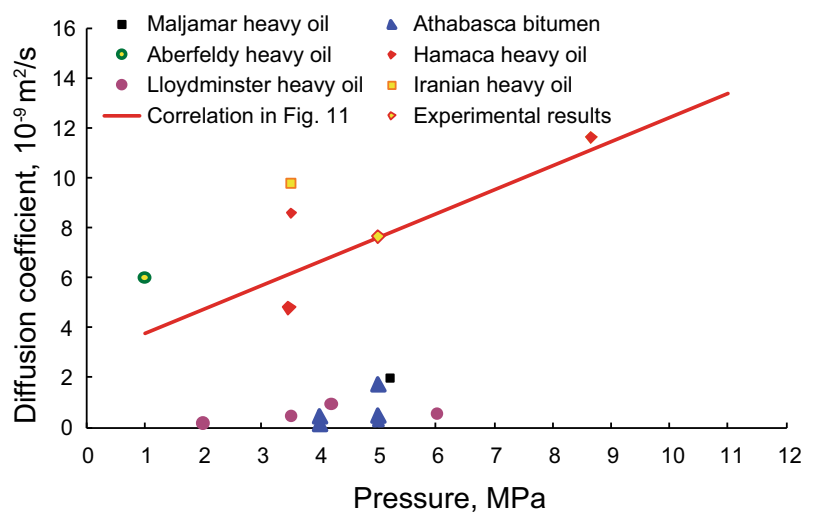

Fig. 12 Comparison of measured diffusion coefficients in different oils

obtained in this study lies in the same range to those in the literature data for Hamaca heavy oil in Venezuela. They are much larger than the gas diffusivities in Lloydminster heavy oil, Athabasca heavy oil, and Maljamar heavy oil

Table 6 Available diffusivity data of gases in bitumens and heavy oils

\begin{tabular}{lllll}
\hline Reference & Pressure, MPa & Temperature, ${ }^{\circ} \mathrm{C}$ & Gas-liquid phase & Diffusivity $10^{-9} \mathrm{~m}^{2} / \mathrm{s}$ \\
\hline Grogan et al. (1988) & 5.2 & 25 & $\mathrm{CO}_{2}$-Maljamar heavy oil & 2 \\
Schmidt (1989) & 5 & $20-200$ & Methane-Athabasca bitumen & $0.28-1.75$ \\
& 5 & 50 & $\mathrm{CO}_{2}$-Athabasca bitumen & 0.5 \\
Nguyen and Farouq Ali (1998) & 1 & 23 & $\mathrm{CO}_{2}$-Aberfeldy heavy oil & 6 \\
Zhang et al. (2000) & 3.51 & 21 & Methane-Hamaca heavy oil & 8.6 \\
& 3.47 & 21 & $\mathrm{CO}_{2}$-Hamaca heavy oil & 4.8 \\
Upreti and Mehrotra (2000) & 4 & $25-90$ & $\mathrm{CO}_{2}$-Athabasca bitumen & $0.16-0.47$ \\
Tharanivasan et al. (2004) & $3.5-4.2$ & 23.9 & $\mathrm{CO}_{2}$-Lloydminster heavy oil & $0.46-0.94$ \\
Yang and Gu (2005) & $2-6$ & 29.3 & $\mathrm{CO}_{2}$-Lloydminster heavy oil & $0.199-0.551$ \\
Jamialahmadi et al. (2006) & 3.5 & 50 & Methane-Iranian heavy oil $_{9}^{9}$ \\
\hline
\end{tabular}


probably because of the different oils and test conditions, such as experimental temperature and method.

\section{Conclusions}

(1) A new model for determining the diffusion coefficient of natural gas in foamy oil, saturated oil, and dead oil was developed based on experimental data. The diffusion coefficient of natural gas in these three types of oil can be predicted accurately and conveniently by determining the slope of the plot of the mass of the oil as it absorbs gas against the square root of time.

(2) During the determination of diffusion coefficient from experimental data, the initial concentration of gas in foamy oil can be obtained by the trapped free gas coefficient which can be obtained by comparing the GOR behavior with pressure in both conventional and unconventional differential liberation PVT tests.

(3) The diffusion coefficients of natural gas in foamy oil are lower than those of gas in saturated oil and dead oil. The diffusion coefficient of natural gas in dead oil is 3.02 and 4.02 times than that of gas in saturated oil and foamy oil when the pressure is $20 \mathrm{MPa}$. However, the gas content of foamy oil is higher than that of saturated oil and dead oil. The gas content of foamy oil is 1.11 and 16.9 times higher than that of saturated oil and dead oil when the dissolution time and pressure are $20 \mathrm{MPa}$ and $35.22 \mathrm{~h}$, respectively.

(4) The diffusion coefficients of natural gas in foamy oil, saturated oil, and dead oil increase lineally with increasing operating pressure. The diffusion coefficient of natural gas in foamy oil at $20 \mathrm{MPa}$ is 2.93 times larger than that at $8.65 \mathrm{MPa}$.

(5) The growth rate of diffusion coefficient with increasing pressure in foamy oil is less than that in saturated oil and dead oil.

\begin{abstract}
Acknowledgments The authors acknowledge the financial support from the Major Subject of National Science and Technology (2011ZX05032-001) and the Fundamental Research Funds for the Central Universities (NO.11CX06022A). The authors wish to express their thanks to Research Institute of Petroleum Exploration and Development, PetroChina for providing oil samples.
\end{abstract}

Open Access This article is distributed under the terms of the Creative Commons Attribution License which permits any use, distribution, and reproduction in any medium, provided the original author(s) and the source are credited.

\section{References}

Bondino I, McDougall SR, Hamon G. A pore-scale modeling approach to the interpretation of heavy oil pressure depletion experiments. J Petrol Sci Eng. 2009;65:14-22.
Dong ZL, Li Y, Liu M, et al. A study of the mechanism of enhancing oil recovery using supercritical carbon dioxide microemulsions. Petrol Sci. 2013;10(1):91-6.

Etminan SR, Maini BB, Chen ZX, et al. Constant-pressure technique for gas diffusivity and solubility measurements in heavy oil and bitumen. Energy Fuels. 2010;24(1):533-49.

Garcia FM. A successful gas-injection project in a heavy oil reservoir. In: 58th annual technical conference and exhibition, San Francisco, California; 1983 (SPE 11988).

Grogan AT, Pinczewski VW, Ruskauff GJ, et al. Diffusion of $\mathrm{CO}_{2}$ at reservoir conditions: models and measurements. SPE Reserv Eng. 1988;2(1):93-102 (SPE 14897).

Guan WL, Wu SH, Zhao J. Utilizing natural gas huff and puff to enhance production in heavy oil reservoir. 2008 SPE international thermal operation and heavy oil symposium, Calgary, Alberta; 2008 (SPE 117335).

Guo P, Deng L, Yang XF, et al. Dry gas huff and puff effect evaluation of gas wells in low-permeable condensate gas reservoirs with rich condensate oil. Petrol Explor Dev. 2010a;37(3):354-7 (in Chinese).

Guo JX, Wang HY, Chen CG, et al. Synthesis and evaluation of an oil-soluble viscosity reducer for heavy oil. Petrol Sci. 2010b;7(4) :536-40.

Hill ES, Lacey WN. Rate of solution of propane in quiescent liquid hydrocarbons. Ind Eng Chem. 1934;26(2):1324-7.

Jamialahmadi M, Emadi M, Müller SH. Diffusion coefficients of methane in liquid hydrocarbons at high pressure and temperature. J Petrol Sci Eng. 2006;53:47-60.

Li SY, Li ZM, Lu T, et al. Experimental study on foamy oil flow in porous media with Orinoco Belt Heavy Oil. Energy Fuels. 2012;26:6332-42.

Liu HB, Xiao LZ, Guo BX, et al. Heavy oil component characterization with multidimensional unilateral NMR. Petrol Sci. 2013a;10(3):402-7.

Liu PC, Wu YB, Li XL. Experimental study of the stability of the foamy oil in developing heavy oil reservoirs. Fuel. 2013b;111:12-9.

Liu SQ, Sun XM, Li SL. Foamy oil recovery mechanism in cold production processes of super heavy oil in Venezuela MPE-3 block. Spec Oil Gas Reserv. 2011;18(4):102-4 (in Chinese).

Mu LX, Han GQ, Xu BJ. Geology and reserve of the Orinoco heavy oil belt, Venezuela. Petrol Explor Dev. 2009;36(6):784-9 (in Chinese).

Mu LX. Development actualities and characteristics of the Orinoco heavy oil belt, Venezuela. Petrol Explor Dev. 2010;37(3): 338-43 (in Chinese).

Mohammad TS, Behnam SS, Fariborz R. Genetic algorithm application for matching ordinary black oil PVT data. Petrol Sci. 2012;9(2):199-211.

Nguyen TA, Farouq Ali S. Effect of nitrogen on the solubility and diffusivity of carbon dioxide into oil and oil recovery by the immiscible WAG process. J Can Petrol Technol. 1998;37(2): 24-31 (SPE 95-64).

Peng J, Guo QT, Kovscek AR. Oil chemistry and its impact on heavy oil solution gas drive. J Petrol Sci Eng. 2009;66:47-59.

Riazi MR. A new method for experimental measurement of diffusion coefficients in reservoir fluids. J Petrol Sci Eng. 1996;14:235-50.

Renner TA. Measurement and correlation of diffusion coefficients for $\mathrm{CO}_{2}$ and rich-gas applications. SPE Reserv Eng. 1988;5(1): 517-23 (SPE 15391).

Schmidt T. Mass transfer by diffusion. In: AOSTRA technical handbook on oil sands, bitumens and heavy oils. Alberta oil sands technology and research authority. Edmonton, Alberta, Canada; 1989.

Sun XF, Zhang YY, Li XM, et al. A case study on foamy oil characteristics of the Orinoco Belt, Venezuela. Adv Petrol Explor Dev. 2013;5(1):37-41. 
Tharanivasan AK, Yang C, Gu Y. Comparison of three different interface mass transfer models used in the experimental measurement of solvent diffusivity in heavy oil. J Petrol Sci Eng. 2004;44:269-82.

Torabi F, Qazvini FA, Kavousi A, et al. Comparative evaluation of immiscible, near miscible and miscible $\mathrm{CO}_{2}$ huff-n-puff to enhance oil recovery from a single matrix-fracture system (experimental and simulation studies). Fuel. 2012;93(3):443-53.

Upreti SR, Mehrotra AK. Experimental measurement of gas diffusivity in bitumen: results for carbon dioxide. Ind Eng Chem. 2000;39(4):1080-7.

Whitman WG. The two-film theory of absorption. Chem Metall Eng. 1923;29:147-52.

Woessner E, Snowden BS, George RA, et al. Dense gas diffusion coefficients for the methane-propane system. Ind Eng Chem. 1969;5(4):780-7.

Wang BJ, Wu YB, Jiang YW, et al. Physical simulation experiments on PVT properties of foamy oil. Acta Petrol Sin. 2012;33(1): 76-9 (in Chinese).
Wang J, Yuan YZ, Zhang LH, et al. The influence of viscosity on stability of foamy oil in the process of heavy oil solution gas drive. J Petrol Sci Eng. 2009;66:69-74.

$\mathrm{Xu} \mathrm{ZY}$, Yue DL, Wu SH, et al. An analysis of the types and distribution characteristics of natural gas reservoirs in China. Petrol Sci. 2009;6(1):38-42.

Yang $\mathrm{CD}$, Gu YA. New experimental method for measuring gas diffusivity in heavy oil by the dynamic pendant drop volume analysis (DPDVA). Ind Eng Chem. 2005;44(12):4474-83.

$\mathrm{Yu}$ CC, Shen SK. Progress in studies of natural gas conversion in China. Petrol Sci. 2008;5(1):67-72.

Zhang YP, Hyndman CL, Maini BB. Measurement of gas diffusivity in heavy oils. J Petrol Sci Eng. 2000;25:37-47.

Zhu GY, Zhang SC, Liu QC, et al. Distribution and treatment of harmful gas from heavy oil production in the Liaohe Oilfield, Northeast China. Petrol Sci. 2010;7(3):422-7. 